\title{
Increased NEK2 in hepatocellular carcinoma promotes cancer progression and drug resistance by promoting PP1/Akt and Wnt activation
}

\author{
SAILAN WEN ${ }^{1,2}$, YUWU LIU ${ }^{3}$, MANYI YANG $^{4}$, KEDA YANG $^{5}$, JIANGHAI HUANG $^{1,2}$ and DEYUN FENG ${ }^{2,5}$ \\ ${ }^{1}$ Department of Pathology, The Second Xiangya Hospital, Central South University, Changsha, Hunan 410011; \\ ${ }^{2}$ Department of Pathology, School of Basic Medical Sciences, Central South University, Changsha, Hunan 410013; \\ ${ }^{3}$ Department of Morphology, The Institute of Advanced Occupation Technology, Xinjiang Medical University, Urumqi, \\ Xinjiang 830011; ${ }^{4}$ National Hepatobiliary and Enteric Surgery Research Center, Department of Surgery, \\ Xiangya Hospital, Central South University, Changsha, Hunan 410008 ; ${ }^{5}$ Department of Pathology, \\ Xiangya Hospital, Central South University, Changsha, Hunan 410008, P.R. China
}

Received March 1, 2016; Accepted July 13, 2016

DOI: $10.3892 /$ or.2016.5009

\begin{abstract}
NIMA-related expressed kinase 2 (NEK2) participates in the carcinogenesis and progression of certain types of cancer, however, its expression and roles in the development of hepatocellular carcinoma (HCC) remains unknown. Here, we found that NEK2 expression was significantly upregulated in both human HCC tissues and cell lines, and increased NEK2 expression in HCC was significantly correlated with clinical progression of $\mathrm{HCC}$ in patients. Knockdown of NEK2 in HCC cells inhibited HCC progression, as determined by the suppressed cell proliferation, invasion and metastasis. Furthermore, knockdown of NEK2 inhibited drug resistance of HCC cells, as shown by the promoted suppression of cell viability in 5-fluorouracil (5-FU)-treated HCC cells. Mechanistically, protein phosphatase 1 (PP1)/Akt and Wnt signaling activation are significantly inhibited by NEK2 knockdown, which is responsible for the HCC progression and involved in NEK2-induced cancer cell abnormal biological behavior. Thus, enhanced NEK2 expression in HCC promotes HCC progression and drug resistance by promoting PP1/Akt and Wnt pathway activation, which may represent a new therapeutic target for HCC.
\end{abstract}

\section{Introduction}

Hepatocellular carcinoma (HCC) is a highly aggressive and heterogeneous disease, and is among the leading causes

Correspondence to: Professor Deyun Feng, Department of Pathology, Xiangya Hospital, Central South University, 87 Xiangya Road, Changsha, Hunan 410008, P.R. China

E-mail: dyfeng743@126.com

Key words: hepatocellular carcinoma, NIMA-related expressed kinase 2, PP1/Akt, Wnt, drug resistance of cancer-related deaths, especially in China (1). Although clinical treatments of HCC have been developed, uncontrolled metastasis and high recurrence lead to poor prognosis of HCC patients. A major reason for HCC-treatment failure is the existence of a drug-resistant subclone, either presenting at diagnosis or development during treatment. Therefore, it is urgent to achieve new treatment options for HCC and explore the molecular mechanisms underlying carcinogenesis and progression of HCC.

NIMA-related expressed kinase 2 (NEK2) as one of chromosomal instability (CIN) genes, is a member of the serine-threonine kinase family NEK, and functional studies have implicated that NEK2 is involved in cell division and mitotic regulation by centrosome splitting $(2,3)$. Increased expression of NEK 2 has been reported in certain cancers, such as breast, cervical, prostate carcinomas, lung cancer, and lymphoma, suggesting the involvement of NEK2 in cancer development (4-8). Additionally, NEK2 has been proven to play pivotal roles in cell proliferation and drug resistance of cancer cells with poor prognosis in myeloma, in which both protein phosphatase 1 (PP1)/Akt and Wnt pathways are involved (9). According to the current network-based interpretation of transcript expression level, NEK2 was significantly elevated in HCC patients compared to normal controls (10). However, despite these studies, the roles of NEK2 in HCC carcinogenesis and progression, especially for drug resistance still remain unknown.

In this study, we investigated the role of NEK2 in HCC development. We found that NEK2 is significantly increased in both HCC tissues and cell lines, and participates in HCC progression and drug resistance. Mechanistically, PP1/Akt and Wnt signaling activation are significantly inhibited by NEK2 knockdown, which implicates the role of NEK2 in promoting HCC progression. Collectively, our data show that enhanced NEK2 expression promotes HCC progression and drug resistance by promoting PP1/Akt and Wnt pathway activation, which may represent a new therapeutic target for HCC. 


\section{Materials and methods}

Clinical samples. There were 64 patients who underwent resection for HCC between 2011 and 2012 at the Department of Hepatobiliary Surgery, the Second Xiangya Hospital of Central South University. None of these patients received chemotherapy or radiotherapy before the operation. The group was composed of 52 men and 12 women at the time of operation. A summary of patient characteristics and pathological features is presented in Table I. Tumor specimens were either cut immediately after removal from the resected hepatic tissues, frozen in liquid nitrogen, and then stored at $-80^{\circ} \mathrm{C}$ or collected in $10 \%$ formalin and then embedded in paraffin for histopathological analysis.

Antibodies, reagents and RNA interference. Phos-Akt (Ser473),

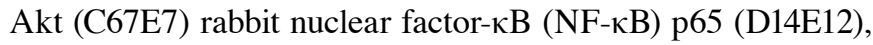
phos-NF-кB p65 (Ser536), phos-GSK3 (Ser9), $\beta$-catenin (D10A8) and $\beta$-actin (8H10D10) used for immunoprecipitation were from Cell Signaling Technology, Inc. Antibodies to NEK2 (ab55550) for western blotting and immunocytochemistry were from Abcam (Cambridge, MA, USA). All antibodies were used according to the manufacturer's instructions. 5-Fluorouracil (5-FU) was purchased from Shanghai Xudong Haipu Pharmaceutical Co., Ltd. (Shanghai, China) and was diluted directly with cell culture medium to the desired concentration. Transient transfection of plasmid DNA was performed using Lipofectamine Plus reagent (Invitrogen) according to the manufacturer's instructions. For RNA interference, siRNAs specific to NEK2, siRNA1 (5'-CAU UUG UUG GCA CAC CUU AUU-3'), siRNA2 (5'-GCU GAG AAA CAG AUG CUU GUU-3') and siRNA3 (5'-UCU GUU GAA GAA CUA CAG CUU-3') were purchased from GenePharma Co., Ltd., and transfected into the cells using Lipofectamine RNAi MAX (Invitrogen) according to the manufacturer's instructions. Non-specific control siRNA (5'-AAG TAG CCG AGCT TCG ATT GC-3') was also used.

Cell culture. HepG2, BEL-7402, QGY-7703, SMMC7721 and Huh-7 were from the Institute of Biochemistry and Cell Biology (Shanghai Institutes for Biological Sciences, CAS). Cells were cultured in RPMI-1640 (Gibco, 31800022; $1.5 \mathrm{~g} / \mathrm{l}$ $\mathrm{NaHCO}_{3}, 2.5 \mathrm{~g} / 1$ glucose, $0.11 \mathrm{~g} / 1$ sodium pyruvate) supplemented with $10 \%$ fetal calf serum (FCS; Invitrogen) in a humidified incubator under $5 \% \mathrm{CO}_{2}$ at $37^{\circ} \mathrm{C}$.

Cell proliferation and half maximal inhibitory concentration $\left(I C_{50}\right)$ values. Cell proliferation was determined using MTT assay of cell proliferation as described before (11). Cells were cultured into a 96-well plate at $1 \times 10^{4}$ cells/well $(n=4$ for each time point) in a final volume of $100 \mu$ l. Cells were cultured for 36-48 $\mathrm{h}$ after transfection with NEK2-siRNA and ctrl-siRNA (non-specific control siRNA), respectively. Then, $20 \mu \mathrm{l}$ MTT $(5 \mathrm{mg} / \mathrm{ml})$ was added to each well $(0.8 \mathrm{mg} / \mathrm{ml}$ final concentration) for further incubation for $4 \mathrm{~h}$. Then the medium was removed, and $100 \mu \mathrm{l}$ DMSO was added to dissolve the solid formazan for $15 \mathrm{~min}$. The absorbance of each well was read at $490 \mathrm{~nm}$ using a microplate reader (Thermo Fisher Scientific, Inc.). For drug resistance assay, cells were stimulated with different concentrations $(0,0.25,0.5,1,20,50$ and $100 \mu \mathrm{g} / \mathrm{ml})$
Table I. Relationship between NEK2 expression and clinicopathological features of HCC.

\begin{tabular}{|c|c|c|c|c|c|}
\hline \multirow[b]{2}{*}{ Characteristics } & \multicolumn{2}{|c|}{ Total } & \multicolumn{3}{|c|}{ NEK2 } \\
\hline & No. & $\%$ & $\begin{array}{l}\text { Positive } \\
\text { case }\end{array}$ & $\%$ & P-value \\
\hline \multicolumn{6}{|l|}{ Age (years) } \\
\hline$\leq 50$ & 33 & 51.6 & 16 & 48.5 & \\
\hline$>50$ & 31 & 48.4 & 18 & 58.1 & 0.443 \\
\hline \multicolumn{6}{|l|}{ Gender } \\
\hline Male & 52 & 81.2 & 25 & 48.1 & \\
\hline Female & 12 & 18.8 & 82.8 & 75 & 0.092 \\
\hline \multicolumn{6}{|l|}{ HBV } \\
\hline Positive & 53 & 82.8 & 28 & 52.8 & \\
\hline Negative & 11 & 17.2 & 6 & 54.5 & 0.917 \\
\hline \multicolumn{6}{|c|}{ Serum AFP (ng/ml) } \\
\hline$\leq 400$ & 49 & 76.6 & 24 & 49 & \\
\hline$>400$ & 15 & 23.4 & 10 & 66.7 & 0.23 \\
\hline \multicolumn{6}{|l|}{ Differentiation } \\
\hline 1 & 7 & 10.9 & 2 & 5.9 & \\
\hline 2 & 15 & 23.4 & 5 & 14.7 & \\
\hline 3 & 42 & 75.7 & 27 & 79.4 & $0.045^{\mathrm{a}}$ \\
\hline \multicolumn{6}{|l|}{ Tumor size $(\mathrm{cm})$} \\
\hline$\leq 5$ & 19 & 29.7 & 4 & 21 & \\
\hline$>5$ & 45 & 70.3 & 30 & 66.7 & $0.001^{\mathrm{a}}$ \\
\hline \multicolumn{6}{|l|}{ Tumor no. } \\
\hline Single & 56 & 87.5 & 30 & 51.8 & \\
\hline Multiple & 8 & 12.5 & 29 & 62.7 & 0.57 \\
\hline \multicolumn{6}{|l|}{$\begin{array}{l}\text { Lymph node } \\
\text { metastasis }\end{array}$} \\
\hline Positive & 5 & 7.8 & 5 & 100 & \\
\hline Negative & 59 & 92.2 & 29 & 49.2 & $0.029^{\mathrm{a}}$ \\
\hline \multicolumn{6}{|c|}{ Hepatic sclerosis } \\
\hline Yes & 30 & 46.9 & 15 & 50 & \\
\hline No & 34 & 53.1 & 19 & 55.9 & 0.638 \\
\hline
\end{tabular}

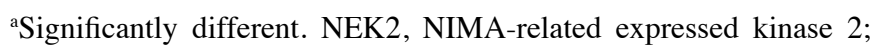
HCC, hepatocellular carcinoma.

of 5-FU in culture medium for $48 \mathrm{~h}$ after transfection with siRNA. The $\mathrm{IC}_{50}$ values were calculated by non-linear regression analysis using SPSS 17.0 software (SPSS, Chicago, IL, USA) as describe before (12).

In vitro cell-invasion and-migration assays. Migration and invasion assay Transwell filters coated with collagen I or Matrigel (8-mm pore size; BD Biosciences) were used for migration or invasion assays, respectively. Cells $\left(1.5 \times 10^{4}\right)$ were seeded into the upper chamber in RPMI-1640 with $0.5 \%$ fetal bovine serum (FBS). The bottom chamber contained RPMI-1640 with $10 \%$ FBS. Cells were allowed to migrate/invade at $37^{\circ} \mathrm{C}$ in $5 \%$ $\mathrm{CO}_{2}$ for $24 \mathrm{~h}$ before they were fixed with methanol/methylene blue solution, stained with crystal violet (Beyotime, Shanghai, 
A

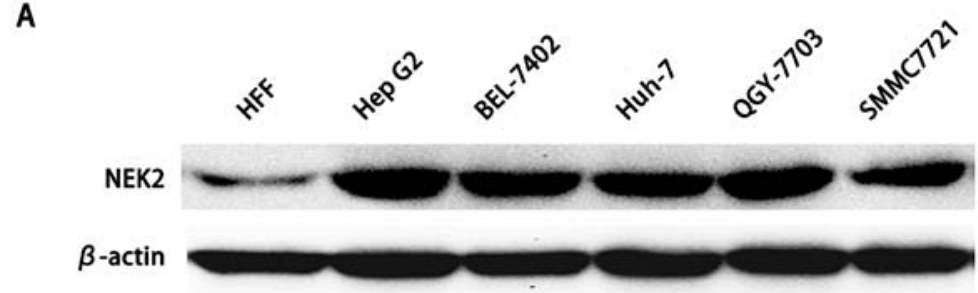

B
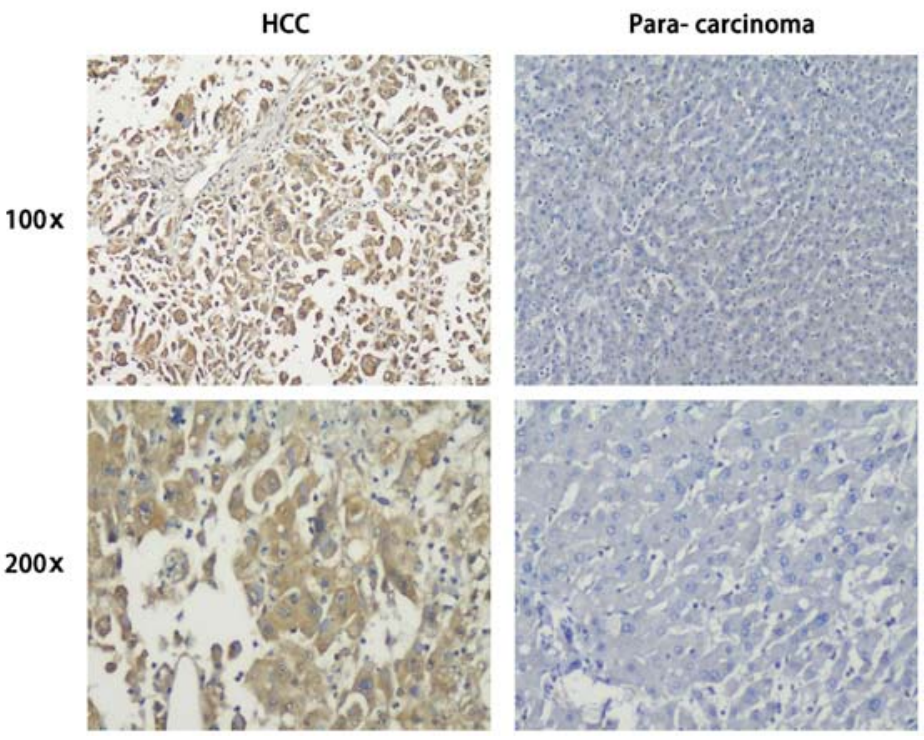

Figure 1. Expression of NIMA-related expressed kinase 2 (NEK2) in cell lines and immunohistochemical staining of NEK2 in hepatocellular carcinoma (HCC) samples. (A) The expression of NEK2 in five human HCC cell lines, HepG2, BEL-7402, QGY-7703, SMMC7721 and Huh-7, by immunoblotting. The HFF (human fibroblast cell line) was used as a negative control. $\beta$-actin was used as an internal control. (B) Immunohistochemical staining of NEK2 in HCC samples, compared with normal para-carcinoma tissue specimens [original magnification, x100 (top row); x200 (bottom row)]. NEK2 immunoreactivity was positively observed in the cytoplasm of cancer cells.

China), imaged, and counted with a microscope (Leica, UK). All experiments were performed in triplicate. Cell counts were performed on 10 fields per filter, and the mean was normalized to the migration/invasion cell count of control cells.

Quantitative real-time PCR. Total RNA was extracted with TRIzol reagent (Invitrogen) following the manufacturer's instructions. Real-time quantitative RT-PCR analysis was performed using the LightCycler (Roche Diagnostics) and SYBR RT-PCR kits (Takara Biotechnology Co., Ltd.). For mRNAs analysis, the primers were: human NEK2 forward, 5'-CCG CCC AAG TCA CAG CAG CAGA-3' and reverse, 5'-GGG AGA AGA GCA GCA GCA GGA AGC-3'; human $\beta$-actin forward, 5'-CAT CCT GCG TCT GGA CCT GG-3' and reverse, 5'-TAA TGT CAC GCA CGA TTT CC-3'; human ABCB1 forward, 5'-AGG CTC GCC AAT GAT GC-3' and reverse, 5'-TCC TGT CCC AAG ATT TGC TAT-3'; human ABCG2 forward, 5'-TGA AAC CTG GTC TCA ACGC-3' and reverse, 5'-AGA GTG CCC ATC ACA ACA TC-3'; human ABCC1 forward, 5'-CGC CTT CGC TGA GTT CCT GC-3' and reverse, 5'-AGT TCT GCG GTG CTG TTG TGG-3'. The relative expression level of mRNAs was normalized to that of internal control GAPDH by using $2^{-\Delta \Delta C}$ cycle threshold method (13).

Cell extraction, protein electrophoresis, and western blotting. Whole cell lysates of QGY-7703 cells were prepared in radioimmunoprecipitation assay buffer $[50 \mathrm{mmol}$ Tris- $\mathrm{HCl}$
(pH 8.0), $150 \mathrm{mmol} \mathrm{NaCl}, 1 \%$ NP40, $0.5 \%$ sodium deoxycholate, and $0.1 \%$ SDS]. Briefly, cells were washed in ice-cold $1 \mathrm{X}$ PBS (pH 7.4) and lysed directly in radioimmunoprecipitation assay buffer on ice for $30 \mathrm{~min}$, centrifuged at $4^{\circ} \mathrm{C}, 14,000 \mathrm{rpm}$, to remove insoluble material and total protein concentration of the resulting supernatant determined by bicinchoninic acid assay (Pierce Biotechnology, Inc., Rockford, IL, USA). Lysate, $50 \mu \mathrm{g}$, for each cell line was resolved by sodium dodecylsulfate-polyacrylamide gel electrophoresis (SDS-PAGE), For immunoblot analysis, protein samples were subjected to SDS-PAGE and transferred onto a nitrocellulose membrane. The membrane was incubated with a primary antibody overnight at $4{ }^{\circ} \mathrm{C}$ after blocking with 5\% skim milk in $0.1 \%$ TBST (Tris-buffered saline with $0.1 \%$ Triton X-100) for $60 \mathrm{~min}$. The second day, the membrane was incubated with a horseradish peroxidase-conjugated secondary antibody for 60 min after washing three times with $0.1 \%$ TBST, then, the membrane was incubated with the ECL solution after washing three times with $0.1 \%$ TBST, and exposed to X-ray film.

Immunocytochemistry and image processing. Immunohistochemical studies on NEK2 were performed on formalin-fixed, paraffin-embedded tissue sections obtained from the aforementioned patients with HCC. Tissue sections were deparaffinized and then boiled in $0.01 \mathrm{~mol} / \mathrm{l}$ sodium citrate buffer ( $\mathrm{pH} 6.0$ ) in a $1,000 \mathrm{~W}$ microwave oven for $10 \mathrm{~min}$ to retrieve cell antigens. The primary antibody used was rabbit 
A

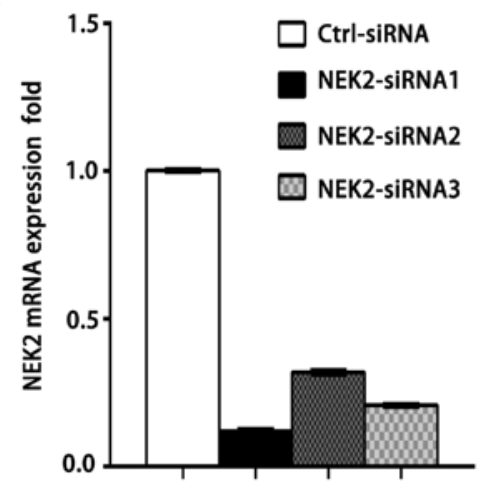

C
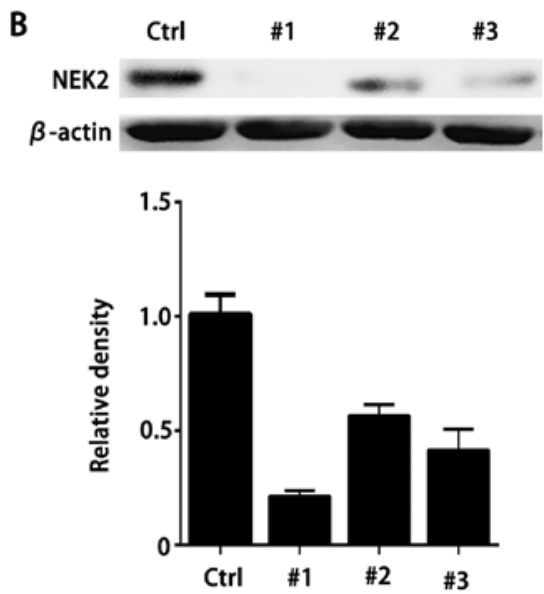

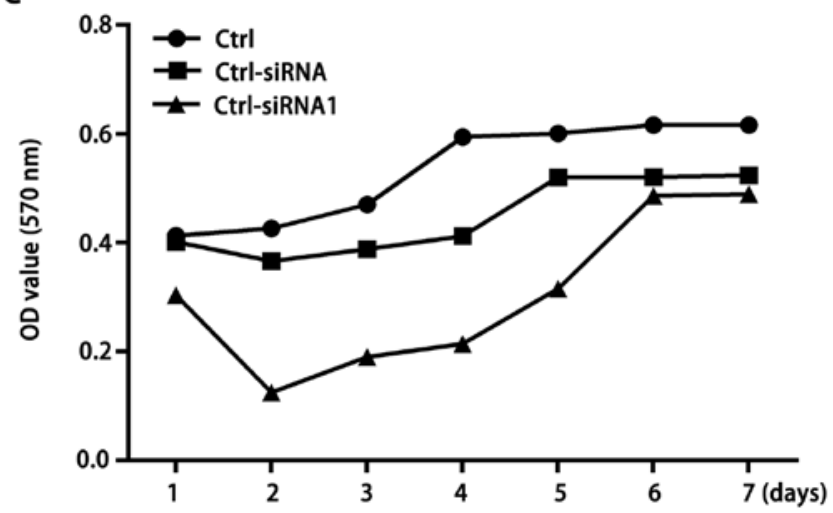

Figure 2. NIMA-related expressed kinase 2 (NEK2) promotes proliferation of hepatocellular carcinoma (HCC) cells. (A and B) At $48 \mathrm{~h}$ transfection with NEK2 siRNA (\#1, NEK2-siRNA1; \#2, NEK2-siRNA2; \#3, NEK2-siRNA3), relative (A) levels of NEK2 mRNA and (B) protein levels were examined by quantitative RT-PCR assay and immunoblotting. Control siRNA (ctrl-siRNA) and $\beta$-actin were used as control, respectively. Results are presented as changed fold concluded with $2^{-\Delta \Delta \mathrm{Ct}}$ cycle threshold method, with relative to (A) ctrl-siRNA transfection-resting set as 1 . The relative density was calculated and is presented as change fold with relative to ctrl-siRNA transfection-resting set as 1. Error bars represent the mean \pm SD of triplicate samples (mRNA) and these data represent one of three independent experiments (protein). (C) Effect of NEK2 siRNA treatment on the relative proliferation of QGY-7703 cells, as assayed by MTT, as described in 'Materials and methods'.

polyclonal NEK2 antibody (1:200 dilution; Bioss, China). All tissue sections were immunohistochemically stained using the avidin-biotin-peroxidase method and were counterstained with hematoxylin. The staining was scored by three independent investigators without knowledge of patient outcomes. The sections were evaluated at low magnification (x100 or x200) to identify areas where NEK2 was evenly stained.

Statistical analysis. The data were subjected to statistical analysis using the SPSS software package (version 17.0). The clinicopathological parameters were tested by $\chi^{2}$ test and bivariate analysis (14). All data are presented as the mean \pm SD. The statistical differences were analyzed by Student's t-test and repeated measures of ANOVA. The differences were considered to be statistically significant at $\mathrm{P}<0.05$.

\section{Results}

NEK2 expression is significantly elevated in HCC. NEK2 is considered an oncogene and is overexpressed in various tumors $(8,15,16)$. In order to examine the roles of NEK2 in HCC development, we examined the expression of NEK2 in HCC tissues and cell lines. As shown in Fig. 1A, compared with negative control HFF (human fibroblast cell line), in HCC cell lines HepG2, BEL-7402, QGY-7703, SMMC7721 and Huh-7, we found that NEK2 was highly expressed. Furthermore, NEK2 expression was significantly increased in HCC tissues as compared to that in the matched non-tumor tissues. Hence, these data confirm that NEK2 expression is significantly increased in both HCC tissues and cell lines, which indicates an important role in $\mathrm{HCC}$ carcinogenesis and progression.

We further examined the correlation between NEK2 and the clinicopathological characteristics of patients with HCC. As summarized in Table I, NEK2 expression was not significantly correlated with age or histological grades. However, NEK2 expression was significantly correlated with tumor size, differentiation grading and lymph node metastasis $(\mathrm{P}=0.001$, 0.045 and 0.029$)$. Together, these data suggest that elevated NEK2 expression in HCC is correlated with the clinical progression of $\mathrm{HCC}$ patients.

NEK2 promotes proliferation of HCC cells. As NEK2 expression is increased in HCC, we next investigated the roles of NEK2 increase in HCC development. RNA interference has emerged as natural and highly efficient mechanism for gene silencing (17-19). In order to test the functional role of NEK2 on cell growth, we have designed three siRNA candidates based on NEK2 gene sequence. Real-time PCR confirmed a remarkable downregulation of NEK2 expression in QGY-7703 cells after transfection of these NEK2-siRNAs (Fig. 2A). Additionally, 
A

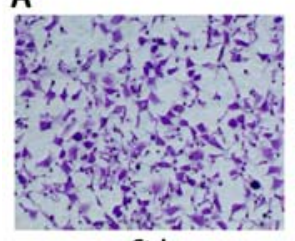

Ctrl

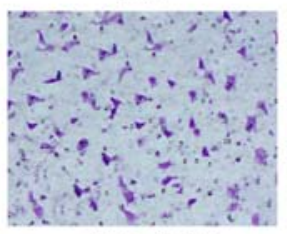

NEK2-siRNA1

C

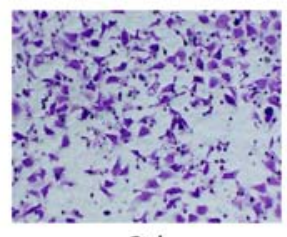

Ctrl

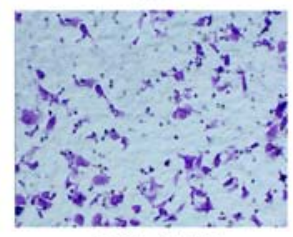

NEK2-siRNA1

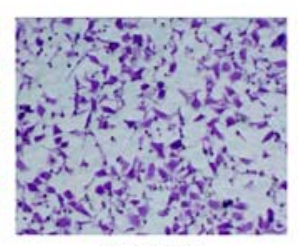

Ctrl-siRNA

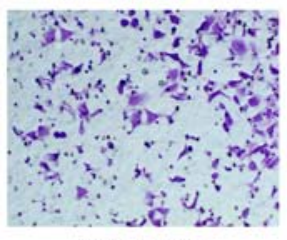

NEK2-SIRNA3
B

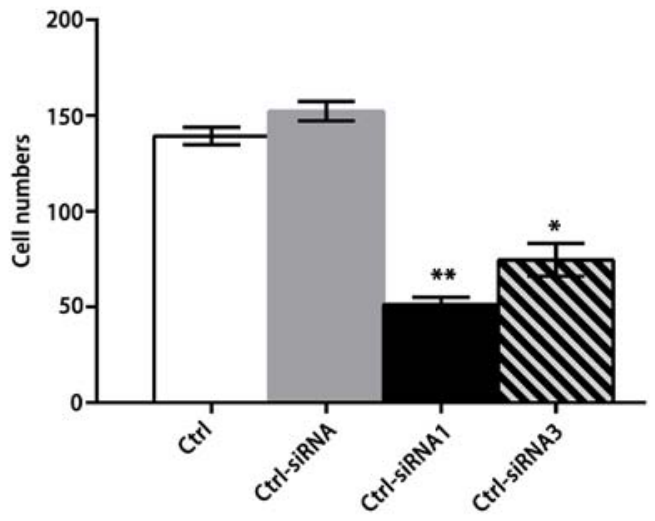

D

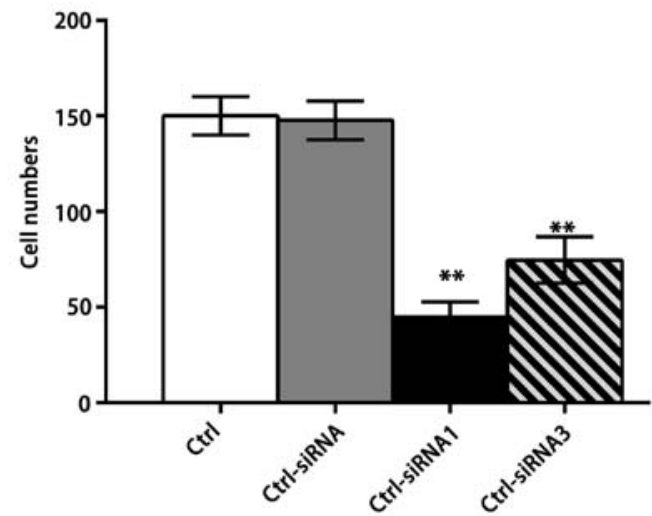

Figure 3. Knockdown of NIMA-related expressed kinase 2 (NEK2) impairs migratory and invasive capacities of hepatocellular carcinoma (HCC) cells. (A) Medium containing 10\% fetal bovine serum (FBS) was placed in the lower chamber, and that without $0.5 \%$ FBS was placed in the upper chamber; siRNA-treated QGY-7703 cells were loaded into the upper migration chamber (left). (B) Migratory cells in the bottom surface of the membrane were counted. Data are expressed as the mean \pm SD from the groups of four samples. ${ }^{*} \mathrm{P}<0.05,{ }^{* *} \mathrm{P}<0.001$. (C) NEK2-siRNA-treated cells and their ctrl-siRNA-treated cells were subjected to invasion assay as described in the 'Materials and methods'. (D) Quantification of invaded cells through Matrigel of each cell treatment are shown. Data are expressed as the mean $\pm \mathrm{SD}(\mathrm{n}=4){ }^{* *} \mathrm{P}<0.001$ is based on the Student's t-test.

relative amounts of NEK 2 protein were decreased by siRNA1, 2 and 3 respectively, compared with those of control siRNA-treated cells (Fig. 2B). In contrast, transfection with control siRNA did not alter NEK2 expression significantly.

We then examined the effect of NEK2 knockdown on cell growth of QGY-7703 cells. As shown in Fig. 2C, the growth of QGY-7703 cells was substantially suppressed by treatment with NEK 2 siRNA1 or 3 compared with control siRNA-treated cells. The results indicate that NEK 2 can promote HCC cell proliferation.

NEK2 promotes migratory and invasive capacities of HCC cells. Because NEK2 controls microtubule organization, overexpressed NEK2 might affect tumor invasion and migration. Therefore, we studied the effect of NEK2 siRNA administration on the invasion and migration of HCC cells. Compared with their control cells and control siRNA-treated cells, knockdown of NEK2 markedly reduced the invasion of QGY-7703 cells (Fig. 3A and B), and also showed significantly impaired migration of QGY-7703 cells (Fig. 3C and D), suggesting that knockdown of NEK2 may dampen the microtubule organization to inhibit their mobility potential. Together with the role of NEK 2 in the promotion of HCC proliferation, we conclude that NEK2 promotes HCC progression.
NEK2 knockdown frustrates drug resistance of HCC cells. We subsequently tested if knockdown of NEK2 expression could decrease drug resistance to fluorouracil injection (5-FU) using insensitive SMMC7721 cell lines. 5-FU inhibited cell proliferation of the SMMC7721 cell lines in a dose-dependent manner (Fig. 4A). Results of $\mathrm{IC}_{50}$ from the representative SMMC7721 were 51.1 $\pm 4.70,48.69 \pm 2.57$ and $15.61 \pm 1.85 \mu \mathrm{g} / \mathrm{ml}$ in SMMC7721 cells non-treated, treated with ctrl-siRNA or NEK2-siRNA, respectively (Fig. 4B). SMMC7721 cells with NEK2 knockdown showed a significant decrease of $\mathrm{IC}_{50}$, indicating that highly elevated NEK2 could promote drug resistance to 5-FU.

NEK2 activates both Akt and canonical Wnt signaling. NEK2 is known to regulate the mitotic centrosome separation through reversible phosphorylation of its substrates PP1 (20) and $\beta$-catenin (21) in yeast, which is also important for cancer cell drug resistance and proliferation (9). Another study demonstrated that the transcriptional level of NEK2 is increased in many aggressive types of cancer, and at least two pathways, PP1/Akt and Wnt signaling, are involved in NEK2-induced cancer cell progression and drug resistance. Consistently, knockdown of NEK2 by siRNA impaired the phosphorylation of Akt, glycogen synthase kinase-3 (GSK3), NF- $\kappa \mathrm{B}$ and 


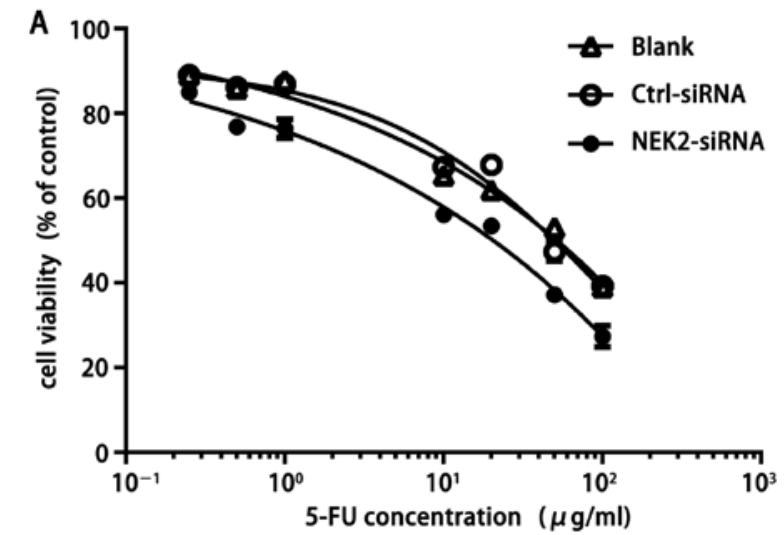

B

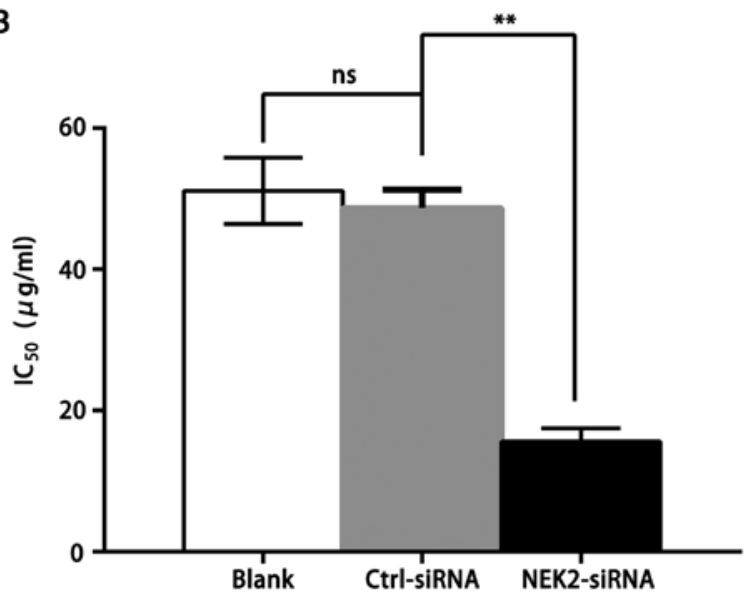

Figure 4. Decreased NIMA-related expressed kinase 2 (NEK2) expression overcomes drug resistance in SMMC7721 cell lines to 5-fluorouracil (5-FU). (A) Dose-response curves, correlating drug dose and cell viability, depict the effects of 5-FU on SMMC7721 cell lines. The cell survival fraction is expressed relative to the untreated cells, set at 100 . The cell numbers are represented as optical density (OD) values. (B) Results of half maximal inhibitory concentration $\left(\mathrm{IC}_{50}\right)$ from the representative SMMC7721 to 5-FU in the representative SMMC7721 cell non-treated and treated with ctrl-siRNA or NEK2-siRNA, respectively. ${ }^{* *} \mathrm{P}<0.001$ (Student's t-test); ns, not significant. Error bars represent the mean \pm SD. Data are from three independent experiments.

decreased nuclear $\beta$-catenin (Fig. 5A), which activates drug resistance and pro-survival gene members. Furthermore, we found that knockdown of NEK2 downregulated mitotic checkpoint protein $\mathrm{ABC}$ transporter family members, including $\mathrm{ABCB} 1$, the drug resistance protein $\mathrm{ABCC} 1$ (MRP1), and the breast cancer resistant protein ABCG2 (BCRP) (Fig. 5B). In addition, knockdown of NEK2 decreased the expression of pro-survival gene members of the BCL2 family (BCL2 and MCL1) in SMMC7721 cell lines, while promoted the pro-apoptotic gene members BAD and BAX, which are suppressed by Akt (Fig. 5C). These results strongly suggest that PP1 and $\beta$-catenin are the downstream targets of NEK2 in HCC cells, and increased NEK2 could contribute to HCC progression by amplifying the PP1/Akt and Wnt pathway.

\section{Discussion}

HCC is the third most common cause of cancer-related deaths worldwide $(22,23)$. NEK2, a member of the NIMA-related family, has several putative roles in cell differentiation, proliferation by centrosome splitting $(3,24)$. Overexpression
A

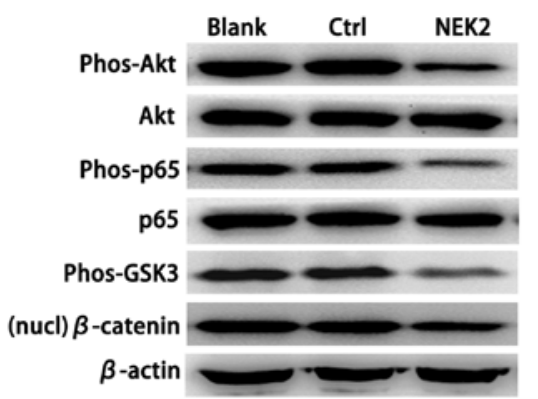

B

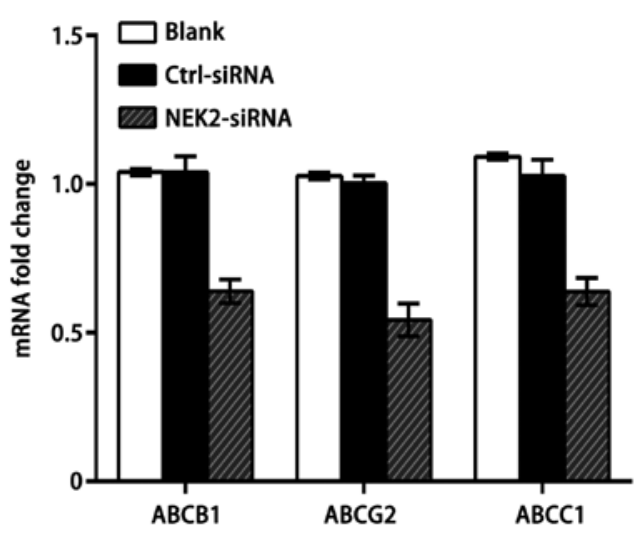

C

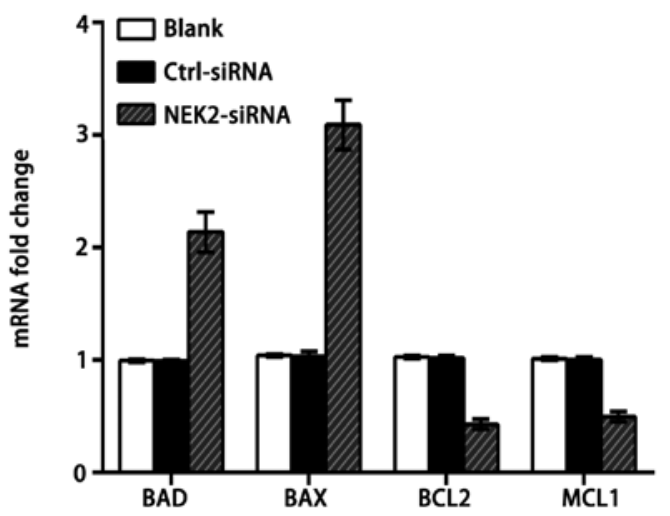

Figure 5. NIMA-related expressed kinase 2 (NEK2) activates both Akt and canonical Wnt signaling pathways in hepatocellular carcinoma (HCC) cells. (A) SMMC7721 was transfected with ctrl-siRNA and NEK2-siRNA or non-treated as blank control. Decreased expression of phos-Akt (Ser-473), phos-GSK3, phos-NF- $\mathrm{kB}$ and decreased nuclear accumulation of $\beta$-catenin were observed on western blotting. $\beta$-actin was used as loading control. These data represent one of three independent experiments. (B and C) The expression of $\mathrm{ABC}$ transporter members (ABCB1, $\mathrm{ABCC} 1$, and $\mathrm{ABCG}$ ), and BCL2 family (BAD, BAX, BCL2 and MCL1) were observed by quantitative RT-PCR assay. $\beta$-actin was used as control. Results are presented as changed fold concluded with $2^{-\Delta \Delta C t}$ cycle threshold method, with relative to ctrl-siRNA transfection-resting set as 1 . Error bars represent the mean $\pm \mathrm{SD}$ of triplicate samples (mRNA) and these data represent one of three independent experiments.

of active NEK2 leads to CIN, cell proliferation and drug resistance, which are also commonly observed in cancers including virtually all myelomas $(9,25)$. Our study showed that centrosomal kinase NEK2 expression was significantly upregulated in HCC cell lines and tissues (Fig. 1). According to Table I, NEK2 expression is correlated with tumor size, differentiation grading and lymph node metastasis, which suggests that NEK2 participates in the clinical progression of HCC patients. Our data also shown that NEK2 is mostly positive in the cytoplasm of the HCC tissue cells and promotes HCC progression and 
drug resistance by amplifying the PP1/Akt and Wnt signaling pathway.

In this study, we found that two pathways, PP1/Akt and Wnt signaling, are involved in NEK2-induced cancer cell progression. It has been revealed that PP1 regulates the Akt signaling pathway to control cell survival, invasion and migration $(26,27)$. Akt functions through IKK to promote the transactivation potential and phosphorylation of $N F-\kappa B(28)$, which activates transcription of pro-survival gene members of the BCL2 family. In the cytoplasm, GSK3 form a $\beta$-catenin destruction complex which mediates the degradation of $\beta$-catenin, which is important for constitutive activation of the canonical Wnt signaling pathway and drives cell proliferation by direct induction of cell cycle regulators $(29,30)$. Our findings support that NEK2 promotes the expression of phosphorylated Akt, GSK3, NF- $\kappa \mathrm{B}$ and increases nuclear accumulation of $\beta$-catenin. Furthermore, we found that knockdown of NEK2 decreased the expression of $\mathrm{ABC}$ transporters, resulting in inhibited drug resistance of HCC cells. Additionally, drug resistance is a universal problem with current cancer therapies. CIN genes have also been associated with acquired or intrinsic drug resistance (31). We demonstrated that targeting NEK2 overcame drug resistance and cell growth of SMMC7721 cells to 5-FU.

In summary, elevated expression of NEK2 in HCC results in both impaired PP1/AKT and Wnt pathways, which are involved in NEK2-induced cancer cell drug resistance, invasion, migration and proliferation. Knockdown of NEK2 by siRNA inhibited QGY-7703 cell growth and decreased drug resistance in vitro. Thus, targeting CIN genes, such as NEK2, have the potential to translate into very important prognostic and therapeutic clinical tools. We are now exploring how NEK2 regulates its downstream targets and how interaction among those pathways is regulated by NEK2 in HCC.

\section{Acknowledgements}

This study was supported by the National Natural Science Foundation of China (81402001). We thank Professor Lifang Yang and Daiqiang Li for their excellent technical assistance.

\section{References}

1. El-Serag HB: Hepatocellular carcinoma. N Engl J Med 365: $1118-1127,2011$.

2. Fry AM: The Nek2 protein kinase: A novel regulator of centrosome structure. Oncogene 21: 6184-6194, 2002.

3. Fletcher L, Cerniglia GJ, Nigg EA, Yend TJ and Muschel RJ: Inhibition of centrosome separation after DNA damage: A role for Nek2. Radiat Res 162: 128-135, 2004.

4. Hayward DG, Clarke RB, Faragher AJ, Pillai MR, Hagan IM and Fry AM: The centrosomal kinase Nek2 displays elevated levels of protein expression in human breast cancer. Cancer Res 64 7370-7376, 2004.

5. Tsunoda N, Kokuryo T, Oda K, Senga T, Yokoyama Y, Nagino M, Nimura $Y$ and Hamaguchi M: Nek2 as a novel molecular target for the treatment of breast carcinoma. Cancer Sci 100: 111-116, 2009.

6. Cappello P, Blaser H, Gorrini C, Lin DC, Elia AJ, Wakeham A Haider S, Boutros PC, Mason JM, Miller NA, et al: Role of Nek2 on centrosome duplication and aneuploidy in breast cancer cells. Oncogene 33: 2375-2384, 2014.

7. Liu X, Gao Y, Lu Y, Zhang J, Li L and Yin F: Upregulation of NEK2 is associated with drug resistance in ovarian cancer. Oncol Rep 31: 745-754, 2014.
8. Zhong X, Guan X, Dong Q, Yang S, Liu W and Zhang L: Examining Nek2 as a better proliferation marker in non-small cell lung cancer prognosis. Tumour Biol 35: 7155-7162, 2014.

9. Zhou W, Yang Y, Xia J, Wang H, Salama ME, Xiong W, Xu H, Shetty S, Chen T, Zeng Z, et al: NEK2 induces drug resistance mainly through activation of efflux drug pumps and is associated with poor prognosis in myeloma and other cancers. Cancer Cell 23: 48-62, 2013.

10. Drozdov I, Bornschein J, Wex T, Valeyev NV, Tsoka S and Malfertheiner P: Functional and topological properties in hepatocellular carcinoma transcriptome. PLoS One 7: e35510, 2012.

11. Min J, Li X, Huang K, Tang H, Ding X, Qi C, Qin X and Xu Z: Phloretin induces apoptosis of non-small cell lung carcinoma A549 cells via JNK1/2 and p38 MAPK pathways. Oncol Rep 34: 2871-2879, 2015.

12. Deng L, Ren Z, Jia Q, Wu W, Shen H and Wang Y: Scheduledependent antitumor effects of 5-fluorouracil combined with sorafenib in hepatocellular carcinoma. BMC Cancer 13: 363 , 2013.

13. Livak KJ and Schmittgen TD: Analysis of relative gene expression data using real-time quantitative PCR and the 2(-Delta Delta C(T)) method. Methods 25: 402-408, 2001.

14. Herbst RS, Heymach JV and Lippman SM: Lung cancer. N Engl J Med 359: 1367-1380, 2008

15. Neal CP, Fry AM, Moreman C, McGregor A, Garcea G, Berry DP and Manson MM: Overexpression of the Nek2 kinase in colorectal cancer correlates with beta-catenin relocalization and shortened cancer-specific survival. J Surg Oncol 110: 828-838, 2014.

16. Zhong X, Guan X, Liu W and Zhang L: Aberrant expression of NEK2 and its clinical significance in non-small cell lung cancer. Oncol Lett 8: 1470-1476, 2014.

17. Jinek M and Doudna JA: A three-dimensional view of the molecular machinery of RNA interference. Nature 457: 405-412, 2009.

18. Moazed D: Small RNAs in transcriptional gene silencing and genome defence. Nature 457: 413-420, 2009.

19. Siomi H and Siomi MC: On the road to reading the RNA-interference code. Nature 457: 396-404, 2009.

20. Helps NR, Luo X, Barker HM and Cohen PT: NIMA-related kinase 2 (Nek2), a cell-cycle-regulated protein kinase localized to centrosomes, is complexed to protein phosphatase 1 . Biochem J 349: 509-518, 2000.

21. Bahmanyar S, Kaplan DD, Deluca JG, Giddings TH Jr, O'Toole ET, Winey M, Salmon ED, Casey PJ, Nelson WJ and Barth AI: beta-Catenin is a Nek2 substrate involved in centrosome separation. Genes Dev 22: 91-105, 2008.

22. Torre LA, Bray F, Siegel RL, Ferlay J, Lortet-Tieulent J and Jemal A: Global cancer statistics, 2012. CA Cancer J Clin 65: 87-108, 2015

23. Jemal A, Bray F, Center MM, Ferlay J, Ward E and Forman D: Global cancer statistics. CA Cancer J Clin 61: 69-90, 2011.

24. Faragher AJ and Fry AM: Nek2A kinase stimulates centrosome disjunction and is required for formation of bipolar mitotic spindles. Mol Biol Cell 14: 2876-2889, 2003.

25. Hayward DG and Fry AM: Nek2 kinase in chromosome instability and cancer. Cancer Lett 237: 155-166, 2006.

26. Xiao L, Gong LL, Yuan D, Deng M, Zeng XM, Chen LL, Zhang L, Yan Q, Liu JP, Hu XH, et al: Protein phosphatase-1 regulates Akt1 signal transduction pathway to control gene expression, cell survival and differentiation. Cell Death Differ 17: 1448-1462, 2010.

27. Brunet A, Bonni A, Zigmond MJ, Lin MZ, Juo P, Hu LS, Anderson MJ, Arden KC, Blenis J and Greenberg ME: Akt promotes cell survival by phosphorylating and inhibiting a Forkhead transcription factor. Cell 96: 857-868, 1999.

28. Dan HC, Cooper MJ, Cogswell PC, Duncan JA, Ting JP and Baldwin AS: Akt-dependent regulation of NF- $\kappa B$ is controlled by mTOR and Raptor in association with IKK. Genes Dev 22: $1490-1500,2008$

29. Fodde R and Tomlinson I: Nuclear beta-catenin expression and Wnt signalling: In defence of the dogma. J Pathol 221: 239-241, 2010.

30. Gehrke I, Gandhirajan RK and Kreuzer KA: Targeting the WNT/beta-catenin/TCF/LEF1 axis in solid and haematological cancers: Multiplicity of therapeutic options. Eur J Cancer 45: 2759-2767, 2009.

31. Kops GJ, Weaver BA and Cleveland DW: On the road to cancer: Aneuploidy and the mitotic checkpoint. Nat Rev Cancer 5: 773-785, 2005. 